\title{
Cognitive Decline, Sensory Impairment, and The Use of Audio-Visual Aids by Long-Term Care Facility Residents
}

\section{Rick Yiu Cho KWAN}

Hong Kong Polytechnic University

\section{Chi Wai KWAN}

University of Hong Kong

\section{Patrick Pui Kin KOR}

Hong Kong Polytechnic University

Iris Chi ( $\nabla$ ichi@usc.edu )

University of Southern California

\section{Research Article}

Keywords: Cognitive decline, Hearing aid, Hearing impairment, Visual aids, Visual impairment

Posted Date: July 26th, 2021

DOl: https://doi.org/10.21203/rs.3.rs-643689/v1

License: (c) (i) This work is licensed under a Creative Commons Attribution 4.0 International License.

Read Full License

Version of Record: A version of this preprint was published at BMC Geriatrics on March 16th, 2022. See the published version at https://doi.org/10.1186/s12877-022-02895-x. 


\section{Abstract}

\section{Background}

Audio-visual impairments and the use of sensory aids are associated with cognitive decline in community-dwelling older people, but effects in long-term care settings are unclear. We hypothesize that visual and hearing impairment are associated with cognitive decline and these relationships are mediated by the use of visual and hearing aids.

\section{Methods}

A secondary data analysis of a longitudinal study was conducted in the 7 government-subsidized longterm care facilities (LTCF) operated by one of the largest non-governmental organizations in Hong Kong using data between 2005 and 2016. Eligible residents were $\geq 60$ years of age without severe cognitive impairment at baseline who had stayed in the facilities for more than three years. All variables were measured by using the Minimum Data Set-Resident Assessment Instrument Version 2.0, Hong Kong version. The outcome was cognitive decline. Predictors were visual and hearing impairments. Mediators were use of visual and hearing aids. General linear models were employed to test the hypotheses.

\section{Results}

Results for 2,233 residents were analyzed, with the mean age of $82.1 \pm 8.2$ years and the mean follow-up period of $4.4 \pm 0.8$ years. Results showed that those who had visual impairment $(p=0.004)$ and hearing impairments $(p=0.022)$ had a higher risk of cognitive decline. Using hearing aids (coefficient $=0.0186$, $p<0.05$ ) positively mediates the effect of hearing impairment on cognitive decline. Using visual aids (coefficient $=-0.0881, p<0.05$ ) negatively mediates the effects of visual impairment on cognitive decline.

\section{Conclusion}

In long-term care settings, hearing and visual impairments are associated with higher risk of cognitive decline. Hearing aids often-users are associated with higher risk of cognitive decline. LTCF residents with visual impairment did not use visual aids. Visual aids protects residents from cognitive decline.

\section{Introduction}

Cognitive decline refers to a longitudinal decline in cognitive function (1). Cognitive decline is mostly explained by ageing, which begins relatively early in adulthood but accelerates after the age of 60 (2). Age-associated cognitive decline can be a normal manifestation of neurodegeneration throughout the process of ageing (3); it is difficult to differentiate between pathological and non-pathological cognitive decline as age-associated cognitive decline is a result of the synergistic effect of pathological (e.g., accumulation of $\beta$-amyloid) and non-pathological (e.g., brain volume loss) causes and it thus varies among individuals (4-6). A faster rate of cognitive decline at the pre-clinical stage (e.g., subjective cognitive decline) is not only associated with an increased risk of dementia (7), but is also strongly 
related to mortality in people with Alzheimer's disease dementia (8). Therefore, cognitive decline is one of the greatest threats to older people's health.

Hearing impairment refers to a reduction in hearing sensitivity that causes difficulty in daily living (9). Hearing impairment is classified into two types: conductive (e.g., cerumen impaction) or sensorineural (e.g., age-related changes) (10). Hearing impairment is prevalent in older people (prevalence rate: 23.3$61.5 \%)$ and the prevalence increases with age $(11,12)$. Visual impairment describes a loss of sight causing difficulty in daily living, and is commonly caused by age-related conditions (e.g., presbyopia, cataract) $(13,14)$. The prevalence rate of visual impairment in older people is reported to be $12.4 \%$, which also increases with age (15).

Hearing aids are common instruments prescribed to or used by older people to improve their audibility, thereby boosting their social interactions and improving their quality of life (16). However, the use of hearing aids by older people with hearing impairment is suboptimal (17). A study reported that there were $70-85 \%$ of the older people with hearing impairment without being prescribed to hearing aids and there were $45 \%$ of those who were prescribed to hearing aids not using them (18), although there is a lack of representable data on the extent of use of hearing aids as reported in a systematic review (19). Reasons for not using hearing aids vary from underestimation of hearing loss by the individual, coping strategies (e.g., poor fit and discomfort), cost, to inappropriate referral $(20,21)$. Visual aids, also known as optical aids, are commonly prescribed (62\%) and used in daily life $(54.8 \%)$ by older people with visual impairment (22). Unlike hearing aids, the majority of older people with visual impairment who are prescribed to visual aids use them regularly (22).

Literature indicates that hearing impairment significantly predicts cognitive decline, mild cognitive impairment, dementia, and Alzheimer's disease in prospective cohort studies (23-25); visual impairment is associated with the risk of dementia and predicts cognitive decline $(26,27)$. Cognitive decline occurred in LTCF residents with dual sensory impairment (i.e., the co-existence of visual and hearing impairment) is faster than in those with only one impairment and those without sensory impairment (28). Recent studies support that the use of a hearing aid by older people could yield benefits on cognitive function (29-32), while unfavourable result was also observed in older people with Alzheimer's disease (33). Observational studies showed that use of hearing aids is associated with a slower cognitive decline $(34,35)$.

Although links between cognitive decline, audio-visual impairment, and hearing aid use were reported in studies, some important knowledge is still missing. First, literature's observation on the protective effect of using hearing aids was mostly in the community - its effect in long-term care settings is unknown. Second, there are few reports on the effect of visual aid use on cognitive decline. The cascade hypothesis theorizes that a cascade starts from sensory loss, communication failure, limited social integration, to decrease in socialization; and these detriments related to sensory loss can cascade directly or indirectly, leading to cognitive impairment (36). In long-term care settings, older people are mostly confined to indoor settings with simpler socialization compared with those dwelling in the community. It is unclear whether sensory aids could ameliorate cognitive decline through the rectification of sensory loss in long- 
term care settings. It is crucial to clarify this point as such knowledge can be used to formulate policies on health screenings if the use of sensory aids eases cognitive decline in older people in long-term care settings.

\section{Objectives}

The objectives of this study, therefore, are to examine 1) the association between sensory impairment and cognitive decline and 2) the mediation effect of the use of audio-visual aids between sensory impairment and cognitive decline. We hypothesize that sensory impairment is associated with cognitive decline and the use of audio-visual aids mediates the effect of sensory impairment on cognitive decline in the longterm care settings.

\section{Methods}

\section{Study Design}

This was a secondary data analysis of a longitudinal study. Secondary data analysis refers to analysis of data that are collected by someone else for another primary purpose (37). Therefore, we report this study by following the guideline of The Reporting of studies Conducted using Observational Routinely-collected health Data (RECORD) Statement (38). The data were collected between January 2005 and December 2016. All methods were performed in accordance with the Declaration of Helsinki and approved by the Human Research Ethics Committee of The University of Hong Kong (Ref No: EA1904045).

\section{Setting}

The study was conducted in the 7 government-subsidized long-term care facilities, also known as Residential Care Services for the Elderly, operated by one of the largest non-governmental organizations in Hong Kong. Their services include residential care, meals, personal care and limited nursing care for elders who suffer from poor health or physical/mild mental disabilities with deficiency in daily living activities but are mentally suitable for communal living (39).

\section{Participants}

Only residents in the dataset who fulfilled the following eligibility criteria were selected for analysis:

\section{Inclusion criteria}

1. Older people as defined by $\mathrm{WHO}$ at age $\geq 60$ years at baseline (40),

\section{Exclusion criteria}


1. Those who had no follow-up data,

2. Those whose baseline cognitive impairment is severe, as defined by a Cognitive Performance Scale score of $\geq 5$ (i.e., possible score range=0-6) (41), as there is limited room for them to decline further, and

3. Those who have resided in the long-term care facilities for less than three years, because the extent of the cognitive decline in three years in people without dementia and with early dementia is relatively small (i.e., 0-2 MMSE points decline/year) (42). Cognitive Performance Scale is less likely to be sensitive enough to identify the minute cognitive decline because each Cognitive Performance Scale point difference varies from 0.8 to 6.3 MMSE points (43).

\section{Data sources and measurement}

The Minimum Data Set-Resident Assessment Instrument Version 2.0 (MDS-RAI 2.0), Hong Kong version, was utilized as the measurement tool $(41,44)$. It is a comprehensive tool measuring LTCF residents' care needs with 22 sections (e.g., cognitive patterns, communication/hearing patterns, vision patterns, and disease diagnosis). The assessment drew on multiple data sources, which included direct questioning of care recipients and caregivers, observation of care recipients in the long-term care environment, and a review of related documents such as medical records. Various trained professionals (nurses, social workers, occupational therapists, and physiotherapists) collected the data following the standardized MDS-RAI 2.0 Users' Manual (45). Nurses monitored the assessment and coordinated the care. The organization conducted in-house standardized training for each assessor. The MDS has been validated and proven to have good criterion validity on many of its sub-scales and good reliability in $80-90 \%$ of items (46). For example, the sub-scale Cognitive Performance Scale has substantial agreement with Minimental State Exam in identification of cognitive impairment (sensitivity=0.94, specificity=0.94, $\mathrm{AUC}=0.96) .(47)$

The data came from a dataset of a project entitled the Hong Kong Longitudinal Study on Long-Term Care Facility (LTCF) Residents, in which all residents in 11 long-term care facilities were repeatedly assessed (44). The exact period between two repeated-assessments could not be precisely controlled because of the availability of the residents (e.g., hospitalization) and the availability of the certified assessors. The period of two repeated-assessments of each resident varied but ranged from six to twelve months. In that project, health data were routinely collected from a cohort of Chinese long-term care residents in Hong Kong to review and improve clinical practices in long-term care facilities. The advantage of using regularly collected clinical data for analysis is that it allows dynamic relationships between variables to be examined over time.

\section{Variables}




\section{Demographic and related clinical profile}

Age, gender, cognitive function at baseline, follow-up year, and related co-morbidities were measured to describe residents' demographic and clinical profiles.

\section{Predictors}

Hearing impairment was measured by the item entitled "Hearing" in the section on Hearing Patterns in the MDS-RAI 2.0. Residents' hearing impairment was quantified to a score ranging from 0 to 3 , which was in turn re-coded as a dichotomous variable. No impairment described being able to adequately hear normal talk, TV, and phone (i.e., Hearing score $=0$ ); impairment level (i.e., Hearing score $=1-3$ ) ranged from having minimal difficulty hearing (e.g., having difficulty hearing when not in a quiet setting) to being highly impaired (e.g., absence of useful hearing).

Visual impairment was measured by the item entitled "Vision" in the section on Vision Patterns in the MDS-RAI 2.0. Residents' visual impairment was quantified to a score ranging from 0 to 4 , which was then re-coded as a dichotomous variable. No impairment (i.e., Vision score $=0-1$ ) referred to seeing fine details adequately, including regular or large print in newspapers or books. Impairment (i.e., Vision score=2-4) either indicated moderately impaired vision (e.g., not able to see newspaper headlines but able to identify objects) or severe impairment (e.g., no vision or only able to see light, colors, or shapes).

Dual sensory impairment was measured by combining the re-coded hearing impairment and visual impairment scores. Residents were categorized as follows: 1) no impairment (i.e., no hearing or visual impairment), 2) one sensory impairment (i.e., having either hearing or visual impairment), and 3) dual impairment (i.e., being both audibly and visually impaired).

\section{Mediators}

Hearing aid use pattern was measured by the item entitled "Communication Devices" in the section on Hearing Patterns in the MDS-RAI 2.0. Residents' use of hearing aids fell into one of these four categories: a) hearing aid present and used, b) hearing aid present and not used regularly, c) other receptive communication techniques used, and d) none of above. The use of hearing aids was re-coded into a 3point categorical variable: 1) hearing aid present and used (i.e., category a), 2) hearing aid present and not used regularly (i.e., category b), and 3 ) having no / not using hearing aids (i.e., combining categories $c$ and d).

Visual aid use was measured by the item entitled "Visual Appliances" in the section on Visual Patterns in the MDS-RAI 2.0. It is a dichotomous variable. Visual aid use denoted the use of glasses, contact lenses, or magnifying glasses. Not using visual aids referred to not using those devices. 


\section{Outcome}

Cognitive decline was captured by the change in cognitive function from baseline to the last time point of observation (i.e., T0-T1). A higher score indicates more severe cognitive decline. Cognitive function was measured using the Cognitive Performance Scale (41), a hierarchical scale assessing cognitive function specifically in five areas: short-term memory, cognitive skills for daily decision-making, the ability to make oneself understood, comatose status, and dependence in eating (41). Scores range from 0 to 6; a higher score entails poorer cognitive function. Cognitive Performance Scale has good inter-rater reliability (Spearman $\rho=0.85)(41)$, as well as good agreement with MMSE $(r=-0.863, p<0.001)$ good criterion validity with MMSE to identify cognitive impairment (sensitivity=0.90-0.94, specificity=0.85-0.95) (47).

\section{Confounders}

Residents' age and gender were measured at baseline in the database. Cognitive function at baseline, which is associated with the subsequent cognitive decline (48), and co-morbidities, including diabetes mellitus (DM), hypertension (HT), stroke, and dementia (49-51), known to confound the effect of sensory impairment on cognitive decline were controlled.

\section{Bias}

Sampling bias was probable since the median length of stay in the long-term-care facilities was 73.4 weeks (i.e., 1.4 years) (52). The majority of the residents were excluded because they were not eligible (i.e., $81.6 \%)$.

\section{Study sample size}

Only 2,233 residents in the 7 long-term care facilities who fulfilled the eligibility criteria were included in the sample.

\section{Statistical methods}

IBM SPSS Statistics 25 was adopted to conduct the statistical analysis. Mean with standard deviation and frequency with percentage were used to describe residents' profiles and related variables in this study. To test the hypotheses \#1, a univariate general linear model was employed, where cognitive decline served as the dependent variable and hearing impairment, visual impairment, and dual sensory impairment served as the independent variables. To test hypothesis \#2, the test of linear moderated mediation using PROCESS macro for SPSS was employed (53). The dependent variable was cognitive decline, independent variables were hearing impairment and visual impairment, and the mediators were the use of hearing aids and visual aids. All models were adjusted for known confounders (i.e., age, gender, 
baseline cognitive function, DM, HT, dementia, and stroke), with 0.05 being the significance level. The estimates of the effects of the predictors were reported using either F-statistics or the estimated marginal mean difference of the outcome (i.e., the CPS change score between categories).

\section{Data access and cleaning methods}

The authors are team members of the "Well-being and Associated Factors of Vulnerable Populations in Long-term Care in Hong Kong" project, entailing our direct access to the database. After extracting data according to the eligibility criteria, we excluded participants with missing data in relation to the variables involved in this analysis.

\section{Results}

\section{Study sample}

As shown in Figure 1, there were 12,141 residents in the dataset. Of these, 9,908 residents were not eligible for inclusion in this study, either because they had no follow-up data $(n=3,992)$, had severe cognitive impairment at baseline $(n=4,157)$, had stayed in the facilities for less than three years $(n=1,754)$, or were younger than $60(n=5)$. After the exclusion of non-eligible residents, 2,233 were left. None of the data on these residents was missing, allowing for subsequent analysis.

\section{Participants' descriptive data}

As shown in Table 1, the mean age of the residents was 82.1 (8.2) years. More residents were female $(n=1,530,68.5 \%)$. The mean Cognitive Performance Scale score at baseline was $1.5(S D=1.2)$; the mean follow-up year was $4.4(S D=0.8)$ years. Most co-morbidities, except hypertension $(n=1,373,61.5 \%)$, were only possessed by a small number of people, including dementia $(n=643,28.8 \%)$, stroke $(n=684,30.6 \%)$, and diabetes $(n=563,25.2 \%)$. A relatively smaller portion of residents have hearing impairment $(n=881$, $39.5 \%)$, visual impairment $(n=338,17.4 \%)$, and dual sensory impairment $(n=273,12.2 \%)$. Most residents had no hearing aids $(n=2,129,95.3 \%)$ and most residents were not using visual aids $(n=1,620,72.5 \%)$ at baseline. The mean decline in the Cognitive Performance Scale score from T0 to T1 was $0.4(S D=0.8)$.

Table 2 exhibits that the visual impairment in the group with no visual aids (visual impairment mean $=1.04$ ) was significantly more severe than in those who did use visual aids (visual impairment mean $=0.86, p<0.001$ ). The group that often used hearing aids (hearing impairment mean=1.73) had worse hearing impairment than the group that had hearing aids but did not use them regularly (hearing impairment mean=1.52), as well as the group without hearing aids (hearing impairment mean=0.50), and the difference was statistically significant $(p<0.001)$. 


\section{Main results}

For the objective \#1, as shown in Table 3, compared with those who had visual impairment, those who had no visual impairment had less cognitive decline (mean difference in CPS change score $=-0.142$, $p=0.004$ ). Compared with those who had hearing impairment, those who did not have hearing impairment had less cognitive decline (mean difference in CPS change score $=-0.083, p=0.022$ ). Compared with those who had dual sensory impairment, those who had single sensory impairment (mean difference in CPS change score $=-0.139, p=0.021$ ) and those who had no sensory impairment (mean difference in CPS change score $=-0.205, p=0.001$ ) had less cognitive decline.

For objective \#2, as shown in Table 4 and Figure 2, the total effect (coefficient=0.0829) and direct effect (coefficient $=0.0749$ ) between hearing impairment and cognitive decline were statistically significant. The indirect effect of a pattern of hearing aid use (i.e., hearing aids present and used) is statistically significant (coefficient=0.0186). However, the indirect effect of another pattern of hearing aid use was not statistically significant. As shown in Table 5 and Figure 3, the total effect (coefficient $=0.0290$ ), direct effect (coefficient=0.0476), and indirect effect of visual aids use (coefficient $=-0.0026$ ) were all statistically significant.

\section{Discussion}

To the authors' best knowledge, this is one of the very few studies demonstrating the protective effect of visual aids on cognitive decline in long-term care settings. It is also among the very few to illustrate the effect of hearing aid use patterns on cognitive decline in long-term care settings. In terms of strength, the data in this study were collected by highly trained and accredited healthcare professional assessors in multiple sites in Hong Kong, and there were no missing data. The key findings of this study are twofold. First, hearing impairment is associated with higher risk of cognitive decline and the hearing aids users have the worst hearing impairment and higher risk of cognitive decline. Second, visual impairment is associated with higher risk of cognitive decline and visual aids users have reduced risk of cognitive.

Residents who often used hearing aids had the most severe hearing impairment. This pattern conveys that in the group of residents who used hearing aids often could not benefit from an adequate restoration of hearing function. This could probably because the hearing impairment in this group is caused by central hearing loss which could not be improved with peripheral amplification, such as hearing aids (54). Another possible reason is that appropriate fitting was not provided to solve the common problems of hearing aids faced by the resident, such as noise interference (55). It is known that there is a progressive hearing loss along ageing and the hearing loss in the 10th decade of life becomes much more significant (i.e., 3.2-3.8dB hearing loss per year) (56). Without regular fitting, the protective effects of hearing aids decline over time. Hearing aid fitting for older residents in LTCF was not routinely performed and the data were not available in the MDS. Evidence shows that regular hearing aid fitting improves the hearing function of the older people and the quality of life of the significant others (57). Therefore, this study 
recommends regular hearing aid fitting and diagnosing causes of hearing loss for LTCF residents and regularly monitored in order to maximize the hearing restorative effects of the hearing aids.

In the literature, using hearing aids slows down the cognitive decline of older people with hearing impairment in community settings (58). Hearing aid is also an important measure to prevent dementia by rectifying the hearing loss (59). Contrasting to these findings, this study found that hearing aids oftenusers are associated with a higher risk of cognitive decline. This is probably because the protective effect of the hearing aids against cognitive decline only happens when hearing aids could improve their audibility (60). In Hong Kong, audibility tests (e.g., pure-tone audiometry) was not regularly conducted among LTCF residents to identify whether their hearing aids were effective to promote hearing function. This study suggests the visiting primary doctor could include or make referral for an audibility test (with and without hearing aids) in the regular medical follow-up and assessment for all the LTCF residents to check whether the hearing aids could actually promote their hearing function. With these data, further analyses could examine whether hearing aids could restore residents' auditability adequately, and subsequently lead to a lower level of cognitive decline.

Visual impairment is associated with increased risk of cognitive decline and use of visual aids protect residents from cognitive decline. This finding agrees with that in the literature (61). The sensory loss consequence theory explains that sensory impairment reduces the ability of the older people to participate in activities, which may decrease brain stimulation and neural reorganization, subsequently leading to cognitive decline $(62,63)$. Having better sensory function may prompt older people to take on more cognitively stimulating tasks to reduce the risk of neurodegeneration (36). Another finding in this study was that the residents who were not using visual aids had more severe visual impairment. This implies that visual aids in this population is under-use. Therefore, this study recommends that regular screening for visual impairment followed by visual aids prescription should take place in LTCF residents to correct their visual function at an earlier stage of visual impairment in order to reduce their risk of cognitive decline. Further studies should examine why the LTCF residents with visual impairment did not use visual aids.

\section{Limitations}

There are several limitations to this study. First, sensory function was assessed by allowing the residents to see or hear with the aids that they commonly used. Therefore, this measurement did not reflect the performance before their use of sensory aids. Instead, it was the performance after considering their pattern of utilization of sensory aids. Second, the visual and hearing functions were not assessed using standardized tools, such as a pure tone audiometry test and visual acuity test, but by residents' functional performance in their daily lives as observed by the caregivers and assessors. However, this is in fact a better reflection of their sensory function performance in daily life. Third, the sensory impairment, the use of sensory aids and the confounders of sensory impairment on cognitive decline were observed at baseline only. The progress of sensory impairment and the confounding factors alongside the cognitive decline over period of longitudinal observation is not known. Forth, the cognitive function was measured 
by the 7-point Cognitive Performance Scale that it may not be sensitive enough to identify minute cognitive decline. Fifth, the use pattern of sensory aids was assessed once in 6-12 months by asking the participants or their caregivers in the LTCF. The internal validity may be threatened by recall bias. Lastly, without information about the hearing aid fitting, whether the observation of that poorer hearing impairment is associated with the use of hearing aids was related to inappropriate hearing aid fitting or other reasons.

\section{Conclusion}

In long-term care settings, hearing and visual impairments are associated with higher risk of cognitive decline. Hearing aids often-users are associated with higher risk of cognitive decline. LTCF residents with visual impairment did not use visual aids. Visual aids protects residents from cognitive decline. To prevent cognitive decline, this study recommends to provide regular screenings for visual impairment with subsequent visual aids prescription. To ensure hearing aids could improve hearing function, regular objective auditability tests with and without hearing aids and regular hearing aid fitting should be conducted among LTCF residents. Further studies should incorporate hearing aid fitting and objectively assessed hearing function to examine whether hearing aids could restore residents' auditability adequately. Also, further studies should examine why the LTCF residents with visual impairment did not use visual aids.

\section{Abbreviations}

\begin{tabular}{|ll|}
\hline CPS & Cognitive Performance Scale \\
\hline HT & Hypertension \\
\hline LTCF & Long-term care facilities \\
\hline MDS & Minimum Data Set \\
\hline $\begin{array}{l}\text { MDS-RAI } \\
2.0\end{array}$ & Minimum Data Set-Resident Assessment Instrument Version 2.0 \\
\hline MMSE & Mini-Mental State Examination \\
\hline RECORD & $\begin{array}{l}\text { The Reporting of studies Conducted using Observational Routinely-collected health } \\
\text { Data }\end{array}$ \\
\hline WHO & World Health Organization \\
\hline
\end{tabular}

\section{Declarations}

\section{Ethics approval and consent to participate}

This study was approved by the Human Research Ethics Committee of The University of Hong Kong (Ref No: EA1904045). This is a secondary data analysis so consent to participate is not applicable. 


\section{Consent for publication}

Not applicable.

\section{Availability of data and material}

The datasets used and/or analysed during the current study available from the corresponding author on reasonable request.

\section{Competing interests}

The authors have no conflicts of interest to declare.

\section{Funding}

This work did not receive funding.

\section{Authors' contributions}

RK, CK, and IC discussed and developed the hypothesis and methods of the study. CR conducted the statistical analysis. RK and PK made the first draft. CK, IC, PK revised the manuscript. All authors have read and approved the manuscript.

\section{Acknowledgements}

Not applicable.

\section{References}

1. Schwartz BS, Stewart W, Bolla KI, Simon D, Bandeen-Roche K, Gordon B, et al. Past adult lead exposure is associated with longitudinal decline in cognitive function. Neurology. 2000;55(8):114450.

2. Salthouse TA. When does age-related cognitive decline begin? Neurobiology of Aging. 2009;30(4):507-14.

3. Cullum S, Huppert FA, McGee M, Dening T, Ahmed A, Paykel ES, et al. Decline across different domains of cognitive function in normal ageing: results of a longitudinal population-based study using CAMCOG. International Journal of Geriatric Psychiatry. 2000;15(9):853-62.

4. Deary IJ, Corley J, Gow AJ, Harris SE, Houlihan LM, Marioni RE, et al. Age-associated cognitive decline. British Medical Bulletin. 2009;92(1):135-52.

5. Mormino EC, Betensky RA, Hedden T, Schultz AP, Amariglio RE, Rentz DM, et al. Synergistic effect of $\beta$-amyloid and neurodegeneration on cognitive decline in clinically normal individuals. JAMA neurology. 2014;71(11):1379-85. 
6. Bishop NA, Lu T, Yankner BA. Neural mechanisms of ageing and cognitive decline. Nature. 2010;464(7288):529-35.

7. Slot RER, Sikkes SAM, Berkhof J, Brodaty H, Buckley R, Cavedo E, et al. Subjective cognitive decline and rates of incident Alzheimer's disease and non-Alzheimer's disease dementia. Alzheimer's \& Dementia. 2019;15(3):465-76.

8. Hui JS, Wilson RS, Bennett DA, Bienias JL, Gilley DW, Evans DA. Rate of cognitive decline and mortality in Alzheimer's disease. Neurology. 2003;61(10):1356-61.

9. Jerger J, Chmiel R, Wilson N, Luchi R. Hearing Impairment in Older Adults: New Concepts. Journal of the American Geriatrics Society. 1995;43(8):928-35.

10. Walling AD, Dickson GM. Hearing loss in older adults. American family physician. 2012;85(12):11506.

11. Mitoku K, Masaki N, Ogata Y, Okamoto K. Vision and hearing impairments, cognitive impairment and mortality among long-term care recipients: a population-based cohort study. BMC Geriatrics. 2016;16(1):112.

12. Roth TN, Hanebuth D, Probst R. Prevalence of age-related hearing loss in Europe: a review. European Archives of Oto-Rhino-Laryngology. 2011;268(8):1101-7.

13. Fricke TR, Tahhan N, Resnikoff S, Papas E, Burnett A, Ho SM, et al. Global Prevalence of Presbyopia and Vision Impairment from Uncorrected Presbyopia: Systematic Review, Meta-analysis, and Modelling. Ophthalmology. 2018;125(10):1492-9.

14. Wang JJ, Mitchell P, Simpson JM, Cumming RG, Smith W. Visual Impairment, Age-Related Cataract, and Mortality. Archives of Ophthalmology. 2001;119(8):1186-90.

15. Evans JR, Fletcher AE, Wormald RPL, Ng ES-W, Stirling S, Smeeth L, et al. Prevalence of visual impairment in people aged 75 years and older in Britain: results from the MRC trial of assessment and management of older people in the community. British Journal of Ophthalmology. 2002;86(7):795-800.

16. Yamada Y, Švejdíková B, Kisvetrová H. Improvement of older-person-specific QOL after hearing aid fitting and its relation to social interaction. Journal of Communication Disorders. 2017;67:14-21.

17. Dillon H, Day J, Bant S, Munro KJ. Adoption, use and non-use of hearing aids: a robust estimate based on Welsh national survey statistics. International Journal of Audiology. 2020:1-7.

18. Lupsakko TA, Kautiainen HJ, Sulkava R. The non-use of hearing aids in people aged 75 years and over in the city of Kuopio in Finland. European Archives of Oto-Rhino-Laryngology and Head \& Neck. 2005;262(3):165-9.

19. Löhler J, Walther LE, Hansen F, Kapp P, Meerpohl J, Wollenberg B, et al. The prevalence of hearing loss and use of hearing aids among adults in Germany: a systematic review. 2019;276(4):945-56.

20. Jenstad L, Moon J. Systematic Review of Barriers and Facilitators to Hearing Aid Uptake in Older Adults. Audiol Res. 2011;1(1):e25-e. 
21. Zazove P, Plegue MA, McKee MM, DeJonckheere M, Kileny PR, Schleicher LS, et al. Effective hearing loss screening in primary care: the early auditory referral-primary care study. 2020;18(6):520-7.

22. Monteiro de Carvalho K, Monteiro GB, Temporini ER, Kara-José N. Acceptance regarding use of optical aids among low vision elderly people. International Congress Series. 2005;1282:60-3.

23. Wei J, Hu Y, Zhang L, Hao Q, Yang R, Lu H, et al. Hearing Impairment, Mild Cognitive Impairment, and Dementia: A Meta-Analysis of Cohort Studies. Dementia and Geriatric Cognitive Disorders Extra. 2017;7(3):440-52.

24. Loughrey DG, Kelly ME, Kelley GA, Brennan S, Lawlor BA. Association of Age-Related Hearing Loss With Cognitive Function, Cognitive Impairment, and Dementia: A Systematic Review and Metaanalysis. JAMA Otolaryngology-Head \& Neck Surgery. 2018;144(2):115-26.

25. Zheng Y, Fan S, Liao W, Fang W, Xiao S, Liu J. Hearing impairment and risk of Alzheimer's disease: a meta-analysis of prospective cohort studies. Neurological Sciences. 2017;38(2):233-9.

26. Davies-Kershaw HR, Hackett RA, Cadar D, Herbert A, Orrell M, Steptoe A. Vision Impairment and Risk of Dementia: Findings from the English Longitudinal Study of Ageing. Journal of the American Geriatrics Society. 2018;66(9):1823-9.

27. Ong SY, Cheung CY, Li X, Lamoureux EL, Ikram MK, Ding J, et al. Visual Impairment, Age-Related Eye Diseases, and Cognitive Function: The Singapore Malay Eye Study. Archives of Ophthalmology. 2012;130(7):895-900.

28. Yamada Y, Denkinger MD, Onder G, Henrard J-C, van der Roest HG, Finne-Soveri H, et al. Dual Sensory Impairment and Cognitive Decline: The Results From the Shelter Study. The Journals of Gerontology: Series A. 2015;71(1):117-23.

29. Glick HA, Sharma AJFiN. Cortical Neuroplasticity and Cognitive Function in Early-Stage, MildModerate Hearing Loss: Evidence of Neurocognitive Benefit From Hearing Aid Use. 2020;14.

30. Anzivino R, Conti G, Di Nardo W, Fetoni AR, Picciotti PM, Marra C, et al. Prospective evaluation of cognitive functions after rehabilitation with cochlear implant or hearing aids: Preliminary results of a multicentric study on elderly patients. 2019;28(3S):762-74.

31. Sarant J, Harris D, Busby P, Maruff P, Schembri A, Lemke U, et al. Effects of hearing aid use on cognition in older adults. 2020;73(7):40-1.

32. Castiglione A, Benatti A, Velardita C, Favaro D, Padoan E, Severi D, et al. Aging, Cognitive Decline and Hearing Loss: Effects of Auditory Rehabilitation and Training with Hearing Aids and Cochlear Implants on Cognitive Function and Depression among Older Adults. Audiology and Neurotology. 2016;21(suppl 1)(Suppl. 1):21-8.

33. Nguyen M-F, Bonnefoy M, Adrait A, Gueugnon M, Petitot C, Collet L, et al. Efficacy of hearing aids on the cognitive status of patients with Alzheimer's disease and hearing loss: a multicenter controlled randomized trial. 2017;58(1):123-37.

34. Maharani A, Dawes P, Nazroo J, Tampubolon G, Pendleton N, group obotS-CW. Longitudinal Relationship Between Hearing Aid Use and Cognitive Function in Older Americans. Journal of the American Geriatrics Society. 2018;66(6):1130-6. 
35. Amieva H, Ouvrard C, Giulioli C, Meillon C, Rullier L, Dartigues J-F. Self-Reported Hearing Loss, Hearing Aids, and Cognitive Decline in Elderly Adults: A 25-Year Study. Journal of the American Geriatrics Society. 2015;63(10):2099-104.

36. Uchida Y, Sugiura S, Nishita Y, Saji N, Sone M, Ueda H. Age-related hearing loss and cognitive decline - The potential mechanisms linking the two. Auris Nasus Larynx. 2019;46(1):1-9.

37. Johnston MPJQ, libraries qmi. Secondary data analysis: A method of which the time has come. 2017;3(3):619- 26.

38. Benchimol El, Smeeth L, Guttmann A, Harron K, Moher D, Petersen I, et al. The REporting of studies Conducted using Observational Routinely-collected health Data (RECORD) statement. PLoS Med. 2015;12(10):e1001885.

39. Elderly Branch of Social Welfare Department. Residential Care Services for Elders Hong Kong2018 [Available from:

https://www.swd.gov.hk/en/index/site_pubsvc/page_elderly/sub_residentia/id_introducti/.

40. World Health Organization. Ageing and health 2019 [Available from: https://www.who.int/newsroom/fact-sheets/detail/ageing-and-health.

41. Morris JN, Fries BE, Mehr DR, Hawes C, Phillips C, Mor V, et al. MDS cognitive performance scale@) Journal of gerontology. 1994;49(4):M174-M82.

42. Adak S, Illouz K, Gorman W, Tandon R, Zimmerman E, Guariglia R, et al. Predicting the rate of cognitive decline in aging and early Alzheimer disease. Neurology. 2004;63(1):108-14.

43. Hutchinson AM, Milke DL, Maisey S, Johnson C, Squires JE, Teare G, et al. The Resident Assessment Instrument-Minimum Data Set 2.0 quality indicators: a systematic review. BMC Health Services Research. 2010;10(1):166.

44. Kwan C-W, Chi I, Lam T-P, Lam K-F, Chou K-L. Validation of Minimum Data Set for Home Care Assessment Instrument (MDS-HC) for Hong Kong Chinese Elders. Clinical Gerontologist. 2000;21(4):35-48.

45. Centers for Medicare \& Medicaid Services. Archived: MDS 2.0 for Nursing Homes 1995 [cited 2020 7th December]. Available from: https://www.cms.gov/Medicare/Quality-Initiatives-PatientAssessment-Instruments/NursingHomeQualitylnits/NHQIMDS20.

46. Poss J, Jutan N, Hirdes J, Fries B, Morris J, Teare G, et al., editors. A review of evidence on the reliability and validity of Minimum Data Set data. Healthcare Management Forum; 2008: SAGE Publications Sage CA: Los Angeles, CA.

47. Hartmaier SL, Sloane PD, Guess HA, Koch GG, Mitchell CM, Phillips CDJTJoGSABS, et al. Validation of the minimum data set cognitive performance scale: agreement with the mini-mental state examination. 1995;50(2):M128-M33.

48. Skoog I, Lithell H, Hansson L, Elmfeldt D, Hofman A, Olofsson B, et al. Effect of Baseline Cognitive Function and Antihypertensive Treatment on Cognitive and Cardiovascular Outcomes: Study on COgnition and Prognosis in the Elderly (SCOPE)*. American Journal of Hypertension. 2005;18(8):1052-9. 
49. Zheng F, Yan L, Yang Z, Zhong B, Xie W. HbA1c, diabetes and cognitive decline: the English Longitudinal Study of Ageing. Diabetologia. 2018;61(4):839-48.

50. Walker KA, Power MC, Gottesman RF. Defining the Relationship Between Hypertension, Cognitive Decline, and Dementia: a Review. Current hypertension reports. 2017;19(3):24.

51. Gorelick PB, Nyenhuis D. Stroke and Cognitive Decline. JAMA. 2015;314(1):29-30.

52. Collingridge Moore D, Payne S, Keegan T, Van den Block L, Deliens L, Gambassi G, et al. Length of stay in long-term care facilities: a comparison of residents in six European countries. Results of the PACE cross-sectional study. BMJ Open. 2020;10(3):e033881.

53. Hayes AF. An Index and Test of Linear Moderated Mediation. Multivariate Behavioral Research. 2015;50(1):1-22.

54. Gates GA. Central presbycusis: an emerging view. Otolaryngology-head and neck surgery: official journal of American Academy of Otolaryngology-Head and Neck Surgery. 2012;147(1):1-2.

55. Levitt $\mathrm{H}$. Noise reduction in hearing aids: A review. Journal of rehabilitation research and development. 2001;38(1):111-22.

56. Wattamwar K, Qian ZJ, Otter J, Leskowitz MJ, Caruana FF, Siedlecki B, et al. Increases in the Rate of Age-Related Hearing Loss in the Older Old. JAMA Otolaryngology-Head \& Neck Surgery. 2017;143(1):41-5.

57. Stark P, Hickson L. Outcomes of hearing aid fitting for older people with hearing impairment and their significant others. International Journal of Audiology. 2004;43(7):390-8.

58. Maharani A, Dawes P, Nazroo J, Tampubolon G, Pendleton N. Longitudinal Relationship Between Hearing Aid Use and Cognitive Function in Older Americans. J Am Geriatr Soc. 2018;66(6):1130-6.

59. Livingston G, Sommerlad A, Orgeta V, Costafreda SG, Huntley J, Ames D, et al. Dementia prevention, intervention, and care. Lancet (London, England). 2017;390(10113):2673-734.

60. Dawes P, Emsley R, Cruickshanks KJ, Moore DR, Fortnum H, Edmondson-Jones M, et al. Hearing loss and cognition: the role of hearing AIDS, social isolation and depression. PloS one. 2015;10(3):e0119616.

61. Zheng DD, Swenor BK, Christ SL, West SK, Lam BL, Lee DJ. Longitudinal associations between visual impairment and cognitive functioning: the Salisbury Eye Evaluation Study. JAMA ophthalmology. 2018;136(9):989-95.

62. Zheng DD, Swenor BK, Christ SL, West SK, Lam BL, Lee DJJJo. Longitudinal associations between visual impairment and cognitive functioning: the Salisbury Eye Evaluation Study. 2018;136(9):98995.

63. Merabet LB, Pascual-Leone AJNRN. Neural reorganization following sensory loss: the opportunity of change. 2010;11(1):44-52.

\section{Tables}


Table 1

Demographics, predictors, and outcomes

\begin{tabular}{|ll|}
\hline Variables & $\mathrm{N}=2,233$ \\
\hline Demographics and related clinical profile & \\
\hline Age, mean (SD) & $82.1(8.2)$ \\
\hline Gender, $\mathrm{n}(\%)$ & $703(31.5)$ \\
Male & $1,530(68.5)$ \\
\hline Female & \\
\hline Cognitive function at baseline (CPS), mean (SD) & $1.5(1.2)$ \\
\hline Follow-up year, mean (SD) & $4.4(0.8)$ \\
\hline Co-morbidities & \\
\hline Dementia, $\mathrm{n}(\%)$ & $643(28.8)$ \\
\hline Stroke, $\mathrm{n}$ (\%) & $684(30.6)$ \\
\hline Diabetes mellitus, $\mathrm{n}(\%)$ & $563(25.2)$ \\
\hline Hypertension, $\mathrm{n}$ (\%) & $1,373(61.5)$ \\
\hline Predictors & $881(39.5)$ \\
\hline Hearing impairment, $\mathrm{n}(\%)$ & \\
\hline Visual impairment, $\mathrm{n}(\%)$ & $388(17.4)$ \\
\hline Dual sensory impairment, $\mathrm{n}(\%)$ & $1,237(55.4)$ \\
\hline No & $723(32.4)$ \\
\hline Single & $273(12.2)$ \\
\hline Dual & \\
\hline Mediators & \\
\hline Hearing aid use pattern, $\mathrm{n}(\%)$ & $(2.5)$ \\
\hline Having no/ Not using hearing aids & \\
\hline Having hearing aids but not regularly used & \\
\hline Having hearing aids and often used & \\
\hline
\end{tabular}




\begin{tabular}{|ll|}
\hline Variables & $\mathbf{N}=2,233$ \\
\hline Visual aid use, $\mathrm{n}(\%)$ & $1,620(72.5)$ \\
Not using visual aids & $613(27.5)$ \\
Using visual aids & \\
\hline Outcome & \\
\hline Change in cognitive function (CPS), mean (SD) & $0.4(0.8)$ \\
\hline CPS=Cognitive Performance Scale & \\
\hline
\end{tabular}

Table 2

Crosstab between sensory impairment and use of aids

\begin{tabular}{|c|c|c|c|c|}
\hline \multicolumn{4}{|c|}{ Visual aids } & P-value \\
\hline \multirow[t]{2}{*}{ n (\%) } & \multicolumn{2}{|l|}{ Yes } & \multicolumn{2}{|c|}{ No } \\
\hline & \multicolumn{2}{|l|}{613 (27.5) } & \multicolumn{2}{|c|}{$1,620(72.5)$} \\
\hline \multirow{2}{*}{$\begin{array}{l}\text { Visual impairment }{ }^{\mathrm{a}} \text {, mean } \\
\text { (SD) }\end{array}$} & $0.86(0.64)$ & & $1.04(0.88)$ & \multirow[t]{2}{*}{$<0.001$} \\
\hline & \multicolumn{3}{|c|}{ Hearing aids } & \\
\hline \multirow[t]{2}{*}{ n (\%) } & $\begin{array}{l}\text { Yes, often } \\
\text { used }\end{array}$ & $\begin{array}{l}\text { Yes, not regularly } \\
\text { used }\end{array}$ & \multirow{2}{*}{$\begin{array}{l}\text { No } \\
2,129 \text { (95.3) }\end{array}$} & \\
\hline & $48(2.1)$ & $56(2.5)$ & & \\
\hline $\begin{array}{l}\text { Hearing impairment }{ }^{\mathrm{b}} \text {, } \\
\text { mean (SD) }\end{array}$ & $1.73(0.87)$ & $1.52(0.76)$ & $0.50(0.74)$ & $<.001$ \\
\hline \multicolumn{5}{|c|}{$\begin{array}{l}\text { a Visual impairment was measured by a } 5 \text {-point scale from MDS-RAI 2.0, with a higher score indicating more severe visual } \\
\text { impairment. }\end{array}$} \\
\hline \multicolumn{5}{|c|}{$\begin{array}{l}\text { b Hearing impairment was measured by a 4-point scale from MDS-RAI2.0, with a higher score indicating more severe hearing } \\
\text { impairment }\end{array}$} \\
\hline
\end{tabular}


Table 3

Associations between visual impairment, hearing impairment, and dual sensory impairment with cognitive decline

\begin{tabular}{|c|c|c|c|c|}
\hline Model & Predictors & $\begin{array}{l}\text { Estimated marginal mean difference in } \mathrm{CPS}^{\mathrm{a}} \\
\text { change score }\end{array}$ & $\mathbf{F}$ & $\begin{array}{l}\text { p- } \\
\text { value }\end{array}$ \\
\hline \multirow[t]{3}{*}{1} & Visual impairment & -0.142 & \multirow[t]{3}{*}{8.426} & \multirow[t]{3}{*}{0.004} \\
\hline & No & 0 & & \\
\hline & Yes & & & \\
\hline \multirow[t]{3}{*}{2} & Hearing impairment & -0.083 & \multirow[t]{3}{*}{5.237} & \multirow[t]{3}{*}{0.022} \\
\hline & No & 0 & & \\
\hline & Yes & & & \\
\hline \multirow[t]{5}{*}{3} & Dual sensory & -0.205 & \multirow[t]{5}{*}{6.083} & 0.002 \\
\hline & & -0.139 & & 0.001 \\
\hline & No & 0 & & \multirow[t]{3}{*}{0.021} \\
\hline & Single & & & \\
\hline & Dual & & & \\
\hline \multicolumn{5}{|c|}{ a CPS=cognitive performance scale } \\
\hline All mode & re adjusted for age, gender, & baseline cognitive function, dementia, diabetes, hypertensio & roke. & \\
\hline
\end{tabular}

Table 4

Total, direct and indirect effects of hearing impairment on cognitive decline.

\begin{tabular}{|ll|}
\hline & Effect coefficient \\
\hline Total & $0.0829^{\star}$ \\
\hline Direct & $0.0749^{\star}$ \\
\hline Indirect & -0.0106 \\
Hearing aids present but not regularly used & $0.0186^{\star}$ \\
Hearing aids present and used & \\
\hline${ }_{\mathrm{p} p<0.05,{ }^{* *} \mathrm{p}<0.01,{ }^{* * \star p}<0.001}$ \\
\hline
\end{tabular}


Table 5

Total, direct and indirect effects of visual impairment on cognitive decline.

\begin{tabular}{|ll|}
\hline & Effect coefficient \\
\hline Total & $0.0450^{*}$ \\
\hline Direct & $0.0476^{\star}$ \\
\hline Indirect & $-0.0026^{\star}$ \\
Use of visual aids & \\
\hline${ }^{* p}<0.05,{ }^{* \star p}<0.01,{ }^{* \star \star} \mathrm{p}<0.001$ \\
\hline
\end{tabular}

\section{Figures}

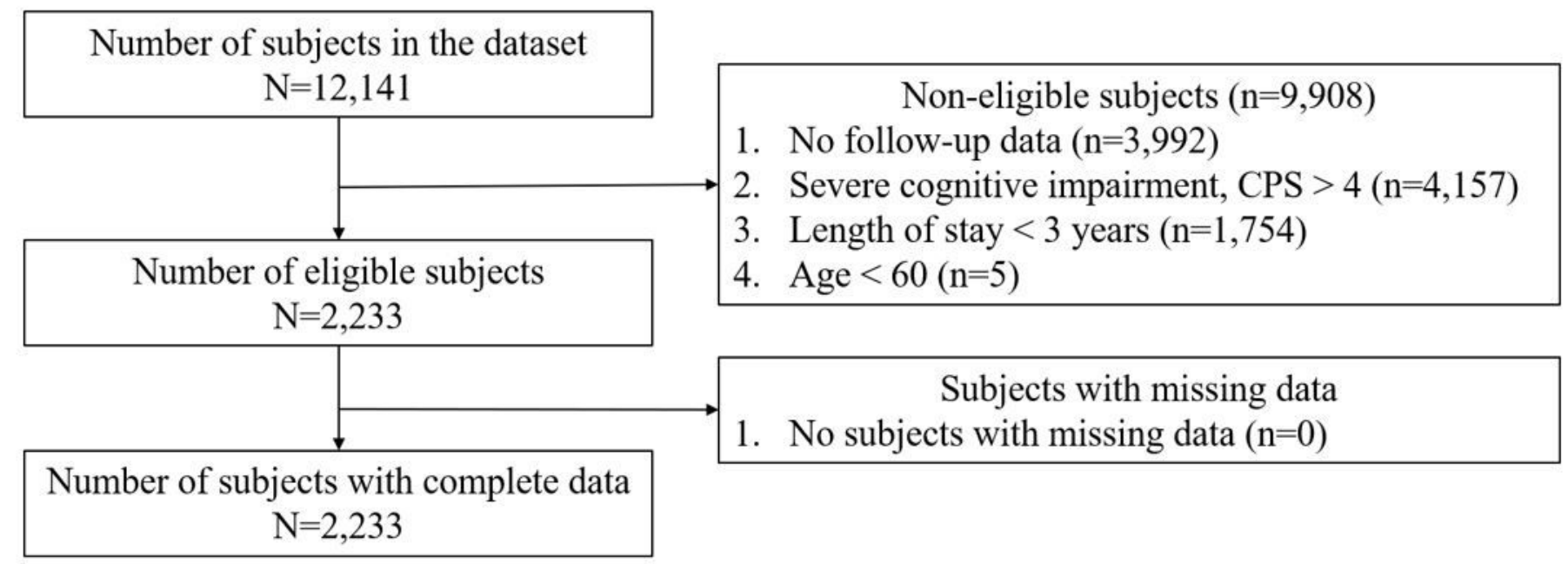

Figure 1

Subject selection flow chart 


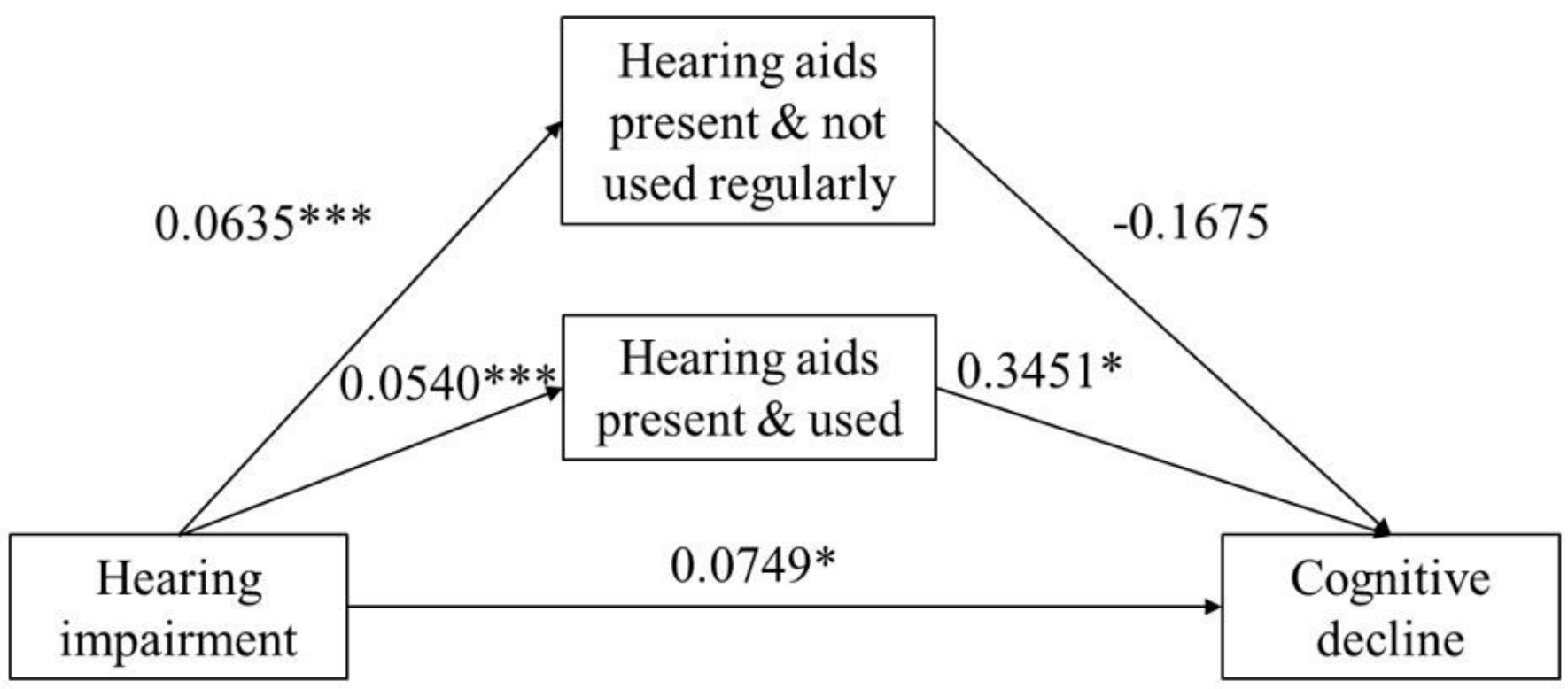

Figure 2

Mediation effects of the use of hearing aids on hearing impairment and cognitive decline

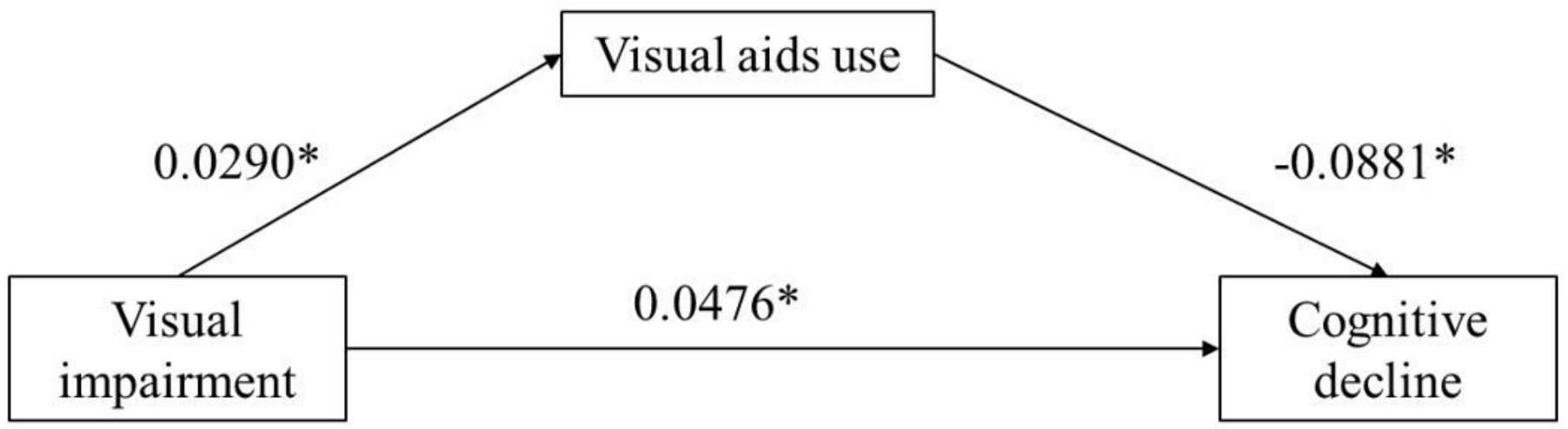

Figure 3

Mediation effects of the use of visual aids on visual impairment and cognitive decline 